\title{
Kinematic calculation of gear reduction gear
}

\author{
Smirnova,ZhannaV. ${ }^{1}$ Vaganova O.I. ${ }^{2}$ Kuznetsova S.N. ${ }^{3}$ Golubeva O.V. ${ }^{4}$,Mikhailov M.S. ${ }^{5}$ \\ ${ }^{1}$ Minin Nizhny Novgorod State Pedagogical University (Minin University), Nizhny Novgorod, Russian Federation, \\ z.v.smirnova@mininuniver.ru \\ ${ }^{2}$ Minin Nizhny Novgorod State Pedagogical University (Minin University), Nizhny Novgorod, Russian Federation, \\ vaganova_o@mail.ru \\ ${ }^{3}$ Minin Nizhny Novgorod State Pedagogical University (Minin University), Nizhny Novgorod, Russian Federation, \\ dens@52.ru \\ ${ }^{4}$ Minin Nizhny Novgorod State Pedagogical University (Minin University), Nizhny Novgorod, Russian Federation, \\ gololga@yandex.ru \\ ${ }^{5}$ Minin Nizhny Novgorod State Pedagogical University (Minin University), Nizhny Novgorod, Russian Federation, \\ mmsss@yandex.ru
}

\begin{abstract}
In this work based on standard calculations according to kinematic gears, a direct gear calculation is performed. A characteristic of the benefits of gearing is given. The kinematic calculations used when choosing an electric motor for a given kinematic scheme are substantiated. A diagram of the geometric parameters of the angle gear is constructed.
\end{abstract}

Key words: Kinematic calculation, gearbox, gear.

\section{INTRODUCTION}

A reducer is a mechanism consisting of gears or worm gears, made in the form of a separate unit and serving to transfer power from the engine to the working machine. The purpose of the gearbox is to reduce the angular velocity and increase the torque of the driven shaft compared to the drive shaft.

When choosing the type of gearbox for the drive of the working body, it is necessary to take into account many factors, the most important of which are: the value and nature of the load change, the required durability, reliability, efficiency, weight and overall dimensions, noise level requirements, product cost, operating costs.

Of all types of gears, gears have the smallest dimensions, mass, cost and friction losses. Toothed gears in comparison with other mechanical gears have great reliability, constant transmission ratio due to lack of slippage, and the possibility of using in a wide range of speeds and gear ratios. These properties provide a large distribution of gears. The disadvantages of gears can be attributed to the requirements of high precision manufacturing and noise when working at significant speeds.In the course project, it is necessary to design a gearbox for the chain conveyor. Chain conveyor is a type of conveyor in which traction is generated by one or two chains. Such conveyors, in comparison with belt conveyors, are capable of transporting goods with high temperature, heavy loads, and they have more productivity.

The gearbox consists of a cast iron housing in which the transmission elements are placed - gear, wheel, bearings, shaft.

\section{RESEARCH}

To select an electric motor, it is necessary to determine the overall efficiency of the gearbox. The overall efficiency of the gearbox is equal to the product of the efficiency of the series-connected movable links: the gear transmission and two pairs of bearings [2].

$\eta_{\text {общ }}=\eta_{1} \cdot \eta_{2}^{2}$, где $\eta_{1}$ - Efficiency gear pair;

$\eta_{2}-$ Efficiency of one pair of rolling bearings. Accept $\eta_{1}=0,98[1]$

$\eta_{2}=0,99[1]$.

Roughly, get: $\eta_{\text {общ }}=0,98 \cdot 0,99^{2} \approx 0,96$

We determine the required power on the high-speed shaft of the gearbox according to the formula [2]:

$\mathrm{P}_{1}=\frac{\mathrm{P}_{2}}{\eta_{\text {общ }}}, \mathrm{kW}$

Where $\mathrm{P}_{2}$ - power on the driven shaft,

$$
\begin{gathered}
\mathrm{P}_{2}=9 \mathrm{~kW} \\
\mathrm{P}_{1}=\frac{9}{0,96}=9,47 \mathrm{~kW}
\end{gathered}
$$

$\mathrm{AtP}_{1}=9,47 \mathrm{~kW}$, и $n_{1}=970 \mathrm{~min}^{-1}$ choose motor type 4A1606У3.

$\mathrm{P}_{\text {эл }}=11 \mathrm{~kW}$

$\mathrm{n}_{\text {эл }}=965 \mathrm{~min}^{-1}$

$\mathrm{n}_{\text {эл }}=\mathrm{n}_{1}=965 \mathrm{~min}^{-1}$

We will carry out a kinematic calculation of the designed gearbox. The kinematic diagram of the designed gearbox is shown in Figure 1.

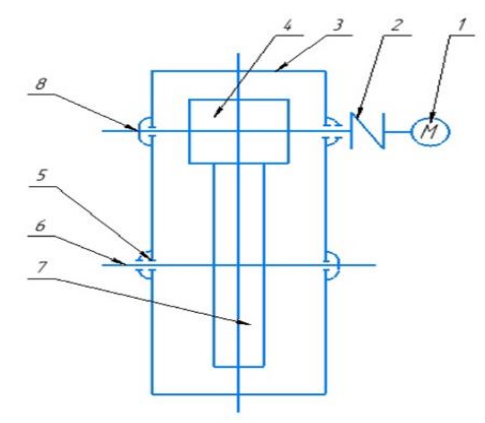

Figure 1: Kinematic diagram of the gearbox 1 - coupling, 2 - electric motor, 3 - gear housing, 4 - drive shaft (shaft - gear), 5 - rolling bearings, 6 - driven shaft, 7 - gear wheel, 8 - bearing cover. 
Smirnova,ZhannaV et al., International Journal of Emerging Trends in Engineering Research, 8(6), June 2020,2422 - 2425

As, since, $\mathrm{n}_{1}=\mathrm{n}_{3}=970 \mathrm{~min}^{-1}$ ии $=2,5-$ standard

determine the speed of the driven shaft according to the formula [2]

Determine the gear ratio [2]

$n_{2}=\frac{n_{1}}{u}$

where $n_{1}$ - drive shaft speed, $n_{1}=970 \mathrm{~min}^{-1}$

$u$-gear ratio, $u=2,5$.

$n_{2}=\frac{970}{2,5}=388 \mathrm{~min}^{-1}$

We find the torque on the shafts by the formula: $\mathrm{T}_{1}=$ $9,55 \cdot \frac{\mathrm{P}_{1}}{n_{1}}, \mathrm{H} \cdot \mathrm{M}$

$$
\begin{gathered}
\mathrm{T}_{1}=9,55 \cdot \frac{9470 \cdot 10^{3}}{965}=93,23 \mathrm{H} \cdot \mathrm{m} \\
\mathrm{T}_{2}=\mathrm{T}_{1} \cdot \mathrm{U} \cdot \eta_{\text {общ }}, \mathrm{H} \cdot \mathrm{m}
\end{gathered}
$$

$\mathrm{T}_{2}=93,23 \cdot 2,5 \cdot 0,96=226,1 \mathrm{H} \cdot \mathrm{m}$

Determine the angular velocity:

$\omega=\frac{\pi n}{30}, \mathrm{~s}^{-1}$

Drive shaft angular speed:

$$
\omega_{1}=\frac{3,14 \cdot 965}{30}=101,6 s^{-1}
$$

The angular speed of the driven shaft:

$$
\omega_{2}=\frac{3,14 \cdot 388}{30}=40,6 s^{-1}
$$

The results of the kinematic calculation are written in the summary table 1 .

Table 1: Kinematic Calculation Results

\begin{tabular}{|c|c|c|}
\hline Design parameters & \multicolumn{2}{|c|}{ Shaft numbers } \\
\cline { 2 - 3 } & \multicolumn{2}{|c|}{$\eta=0,96$} \\
\hline $\begin{array}{c}\text { General gearbox } \\
\text { efficiency } \eta\end{array}$ & \multicolumn{2}{|c|}{$\mathrm{U}=2,5$} \\
\hline Shaft speed $\mathrm{n}, \mathrm{min}^{-1}$ & 965 & 388 \\
\hline Gear ratio U & \multicolumn{2}{|c|}{9} \\
\hline Power P, $\mathrm{kW}$ & 93,23 & 226,1 \\
\hline $\begin{array}{c}\text { Rotational moment T, } \\
\text { H·m }\end{array}$ & 101,6 & 40,6 \\
\hline Angular velocity, $\mathrm{s}^{-1}$ & \multicolumn{2}{|c|}{} \\
\hline
\end{tabular}

For further design of the gearbox, it is necessary to choose the material of gears with the definition of permissible stresses.

We select the material for the manufacture of gears and gears and determine the permissible stresses.

According to the steel tables, we assign steel to manufacture the gears 40XHwith hardness 269...302HBheat treated improvement.

$$
H B_{1}=\frac{(269+302)}{2}=285,5 \mathrm{kgf} / \mathrm{mm}^{2}
$$

According to the composition table of alloy steels, we assign steel to manufacture the gear wheel 40XHwith hardness $235 \ldots 262 \mathrm{HB}$ with heat treatment improvement.

$$
H B_{2}=\frac{(235+262)}{2}=248,5 \mathrm{\kappa г \textrm {c }} / \mathrm{мM}^{2}
$$

Permissible contact stress for gear teeth is calculated by the formula [3]

$$
\begin{aligned}
{[\sigma]_{H_{1}} } & =\mathrm{K}_{\mathrm{HL}} \cdot[\sigma]_{\mathrm{HO}_{1}} \\
{[\sigma]_{H_{2}} } & =\mathrm{K}_{\mathrm{HL}} \cdot[\sigma]_{\mathrm{HO}_{2}}
\end{aligned}
$$

where $\mathrm{K}_{\mathrm{HL}}$ - gear teeth longevity coefficient;
$[\sigma]_{\mathrm{HO}_{1}}$ and $[\sigma]_{\mathrm{HO}_{2}} \quad$ - permissible contact stresses corresponding to the number of cycles of alternating stresses NH0.

$$
K_{H L}=\sqrt[6]{\frac{N_{H O}}{N_{1}}}
$$

where $N_{H 0}$ - the number of cycles of voltage changes corresponding to the endurance limit, according to the table 3.3. [2] $\operatorname{accept} N_{H 0}=16,5 \cdot 10^{6}$;

$\mathrm{N}_{1}$ - the number of voltage change cycles for the entire service life (operating time)

$N_{1}=573 * \omega_{1} * L_{h}$

Where $\omega_{1}-$

angularvelocityoft hecorrespondingshaft $L_{h}$ - drive service life (resource),

$\mathrm{N}_{1}=573 \cdot 101,6 \cdot 15000=868 \cdot 10^{6}$

$$
L_{h}=15000 \text { hours }
$$

$N_{H O}=16,5 * 10^{6}$

If $\mathrm{N}_{1}>N_{H O}$ hence $K_{H L}=1$

According to table 3.1. [2] determine the permissible contact voltage,

corresponding to the number of voltage change cycles

$N_{H 0}$.

$[\sigma]_{\mathrm{HO}_{1}}=1,8^{*} H_{\mathrm{cp}}+67-$ for gear

$[\sigma]_{\mathrm{HO}_{1}}=1,8 * 285,5+67=580,9 \mathrm{H} / \mathrm{mm}^{2}$

$[\sigma]_{\mathrm{HO}_{2}}=1,8 * H_{\mathrm{cp}}+67-$ for wheel

$[\sigma]_{\mathrm{HO}_{2}}=1,8 * 248,5+67=514,3 \mathrm{H} / \mathrm{mm}^{2}$

Substitute the resulting values in the formula: $[\sigma]_{\mathrm{H} 1}=$ $1 * 580,9=580,9 \mathrm{H} / \mathrm{mm}^{2}$

Determine the allowable contact stress for the teeth of the wheel, substitute in the formula: $[\sigma]_{\mathrm{H} 2}=1 * 514,3=514,3$ $\mathrm{H} / \mathrm{mm}^{2}$

As $H B_{1}-H B_{2}=285,5-248,5=37=20 \ldots 50$, then the gear is calculated for strength at a lower value $[\sigma]_{H}$ from received for gear $[\sigma]_{H 1}$ and wheels $[\sigma]_{H 2}$, i.eon less durable teeth [4]

In this way, $[\sigma]_{H}=513 \mathrm{H} / \mathrm{mm}^{2}$

Define the allowable bending stress for the gear $\operatorname{teeth}[\sigma]_{F 1}$ and wheels $[\sigma]_{F 1}[2,6]$

\begin{tabular}{|c|c|c|c|c|c|c|c|}
\hline \multirow[t]{2}{*}{$\begin{array}{c}\text { Transmissi } \\
\text { on item }\end{array}$} & \multirow[t]{2}{*}{$\begin{array}{l}\text { steel } \\
\text { grade }\end{array}$} & \multirow{2}{*}{$\begin{array}{l}D_{\text {пред }} \\
\vdots \\
S_{\text {пред. }}\end{array}$} & \multirow{2}{*}{$\begin{array}{l}\text { Heat } \\
\text { treatmen } \\
\mathrm{t}\end{array}$} & \multirow[t]{2}{*}{$\begin{array}{l}\mathrm{HB}_{1 \mathrm{cp}} \\
\mathrm{HB}_{2 \mathrm{cp}}\end{array}$} & $\sigma_{B}$ & {$[\sigma]_{H}$} & {$[\sigma]_{H}$} \\
\hline & & & & & \multicolumn{3}{|c|}{$\mathrm{H} / \mathrm{mm}^{2}$} \\
\hline Gear & $40 \mathrm{XH}$ & \begin{tabular}{|l|}
200 \\
MM \\
125 \\
MM \\
\end{tabular} & $\begin{array}{c}\text { Improve } \\
\text { ment }\end{array}$ & 285,5 & 920 & $\begin{array}{l}580, \\
9\end{array}$ & 220,5 \\
\hline Wheel & $40 \mathrm{XH}$ & \begin{tabular}{|l|}
115 \\
MM \\
200 \\
MM \\
\end{tabular} & $\begin{array}{c}\text { Improve } \\
\text { ment }\end{array}$ & 248,5 & 800 & $\begin{array}{l}514, \\
3\end{array}$ & 192 \\
\hline
\end{tabular}

We accept the coefficient of durability for gears and wheels $K_{F L_{1}}=1$

$$
\begin{aligned}
& {[\sigma]_{F 1}=K_{F L 1} \cdot[\sigma]_{F 01},} \\
& {[\sigma]_{F 2}=K_{F L 2} \cdot[\sigma]_{F 02},}
\end{aligned}
$$

where $[\sigma]_{\mathrm{F} 0}$ - permissible bending stress corresponding to the number of cycles of alternating stresses $N_{F O}$.

$K_{F^{-}}$gear ratio;

$K_{F L_{1}}=1 ; K_{F L_{2}}=1$

Calculations of the gear are listed in table 2.

Table 2: Design Gear Design 
Smirnova,ZhannaV et al., International Journal of Emerging Trends in Engineering Research, 8(6), June 2020,2422 - 2425

\section{RESULT AND DISCUSSED}

According to the calculations of the gear transmission and the choice of the electric motor, we will carry out a final study of the basic geometric parameters of the transmission.

Determine the center distance according to the formula [5]

where $K_{a}$ - Bauxiliary factor.

$$
a_{\mathrm{w}}=K_{a}(u+1) \cdot \sqrt[3]{\frac{T_{2} \cdot 10^{3}}{\psi_{a} \cdot u^{2} \cdot[\sigma]_{H}^{2}} \cdot K_{H \beta}}
$$

For helical gears $K_{a}=43$

$\mathrm{u}-$ gear ratio, $\mathrm{u}=2,5$

$T_{2}$ - torque on a low-speed shaft when calculating the gearbox, $\quad T_{2}=226,1 \mathrm{H} \cdot \mathrm{M}$

$\psi_{a}$ - rim width ratio, $\psi_{a}=0,3$

$K_{H \beta}$ - coefficient of uneven load along the length of the tooth

$$
K_{H \beta}=1
$$

$[\sigma]_{H}$ - permissible contact stress of the wheel with a less durable tooth;

$$
\begin{aligned}
& {[\sigma]_{H}=514,3 \mathrm{H} / \mathrm{mm}^{2}} \\
& a_{\mathrm{w}}=43 \cdot(2,5+1) \cdot \sqrt[3]{\frac{226,1 \cdot 10^{3}}{0,3 \cdot 2,5^{2} \cdot 514,3^{2}} \cdot 1}=
\end{aligned}
$$$$
150,3 \sqrt[3]{\frac{226100}{495946}}=127,5 \mathrm{~mm}
$$

According to the value tables, we take aw for the series $\mathrm{Ra}$ 40 equal to $130 \mathrm{~mm}$.

Determine the modulus of engagement [2]

$$
m_{n} \geq \frac{2 K_{m} \cdot T_{2} \cdot 10^{3}}{d_{2} \cdot b_{2} \cdot[\sigma]_{F}}
$$

where $\mathrm{K}_{\mathrm{m}}$ - auxiliary ratio, for helical gears

$$
\begin{aligned}
& \mathrm{K}_{\mathrm{m}}=5,8 \\
& \mathrm{~b}_{2}=\psi_{\mathrm{a}} \cdot \mathrm{a}_{\mathrm{W}}=0,3 \cdot 130=39 \mathrm{~mm}-\text { gear } \mathrm{rim}
\end{aligned}
$$

width; $[\sigma]_{\mathrm{F}}=192 \mathrm{H} / \mathrm{mm}^{2}$ - permissible bending stress of the material of the wheel with a less strong tooth; $\mathrm{d}_{2}-$ pitch wheel diameter:

$$
\begin{aligned}
& \mathrm{d}_{2}=\frac{2 \cdot a_{w} \cdot u}{(u+1)}=\frac{2 \cdot 130 \cdot 2,5}{(2,5+1)}=185,7 \mathrm{~mm} \\
& m_{n} \geq \frac{2 \cdot 5,8 \cdot 226,1 \cdot 10^{3}}{185,7 \cdot 39 \cdot 192}=2,52 \mathrm{~mm}
\end{aligned}
$$

Accepted by a number of standard numbers $m_{n}=2,75 \mathrm{~mm}$ Determine the angle of inclination of the teeth $\beta_{\text {min }}$ for helical gearing [2] $\beta_{\min }=\arcsin \frac{3,5 \cdot m_{n}}{b_{2}}$

$b_{2}=\psi_{a} \cdot a_{\mathrm{w}}$-wheel rim width

$b_{2}=0,3 \cdot 130=39 \mathrm{~mm}$

$\beta_{\text {min }}=\arcsin \frac{3,5 \cdot 2,75}{39}=\arcsin 0,2467=14,2823^{\circ}$

wheels:

Determine the total number of gear teeth and

Number of Teeth:

$z_{\Sigma}=z_{1}+z_{2}=\frac{2 \cdot a_{w} \cdot \cos \beta_{\min }}{m_{n}}$

гдеа $\omega_{\omega}$ - center distance

$\mathrm{a}_{\omega}=130 \mathrm{~mm}$;

$\beta$ - tooth angle,

$\beta=14,2823^{\circ}$;

$\mathrm{m}$ - engagement module,

$\mathrm{m}=2,75 \mathrm{~mm}$

$Z_{\Sigma}=\frac{2 \cdot 130 \cdot 0,969}{2,75}=91$

$z_{2}=z_{\Sigma}-z_{1}=91-26=65$
We specify the actual value of the angle of inclination of the teeth:

$$
\begin{aligned}
& \cos \beta=\frac{\left(z_{1}+z_{2}\right) \cdot m_{n}}{2 \cdot a_{w}} \\
& \cos \beta=\frac{(26+65) \cdot 2,75}{2 \cdot 130}=0,9625 \\
& \beta=15^{\circ} 18^{\prime}
\end{aligned}
$$

Determine the number of gear teeth:

$z_{1}=\frac{z_{\Sigma}}{(u+1)}$

$$
z_{1}=\frac{91}{(2,5+1)}=\frac{91}{3,5}=26
$$

Determine the actual center distance $u_{\phi}$ and check its deviation $\Delta$ ufrom a given $\mathrm{u}$ :

$$
\begin{aligned}
& u_{\phi}=\frac{z_{2}}{z_{1}} \\
& u_{\phi}=\frac{65}{26}=2,5 \\
& \Delta \mathrm{u}=\frac{\left|u_{\phi}-u\right|}{u} \cdot 100 \% \leq 4 \% \\
& \Delta \mathrm{u}=\frac{|2,5-2,5|}{2,5} \cdot 100 \% \leq 4 \% \\
& 0 \%<4 \%
\end{aligned}
$$

Determine the actual center distance:

$$
\begin{aligned}
& a_{\mathrm{w}}=\frac{\left(z_{1}+z_{2}\right) \cdot m_{n}}{2 \cdot \cos \beta} \\
& a_{\mathrm{w}}=\frac{(26+65) \cdot 2,75}{2 \cdot 0,9625}=130 \mathrm{~mm}
\end{aligned}
$$

Determine the actual basic geometric transmission parameters, mm:

Gear pitch and wheel pitch diameters:

$$
\begin{aligned}
& d_{1}=\frac{m_{n}}{\cos \beta} \cdot z_{1} \\
& d_{2}=\frac{m_{n}}{\cos \beta} \cdot z_{2}
\end{aligned}
$$

Wherem- engagement module, $m=2,75 \mathrm{~mm}$;

$\beta$ - tooth angle, $\beta=15^{\circ} 18^{\prime}$;

$z_{1}$ - gear teeth, $z_{1}=26$.

$d_{1}=\frac{2,75}{0,9625} \cdot 26=74,3 \mathrm{~mm} ;$

$d_{2}=\frac{2,75}{0,9625} \cdot 65=185,7 \mathrm{~mm} ;$

The diameters of the tops of the gear teeth:

$d_{\mathrm{a}_{1}}=d_{1}+2 \cdot m_{n}$

$d_{\mathrm{a}_{1}}=74,3+2 \cdot 2,75=79,8 \mathrm{~mm} ;$

The diameters of the tops of the teeth of the wheel:

$d_{\mathrm{a}_{2}}=d_{2}+2 \cdot m_{n}$

$d_{\mathrm{a}_{2}}=185,7+2 \cdot 2,75=191,2 \mathrm{~mm} ;$

The diameters of the cavities of the gear teeth:

$d_{f_{1}}=d_{1}-2,4 \cdot m_{n}$

$d_{f_{1}}=74,3-2,4 \cdot 2,75=67,7 \mathrm{~mm}$;

Wheel tooth hollow diameters:

$d_{f_{2}}=d_{2}-2,4 \cdot m_{n}$ 
Smirnova,ZhannaV et al., International Journal of Emerging Trends in Engineering Research, 8(6), June 2020,2422 - 2425

$d_{f_{2}}=191,2-2,4 \cdot 2,75=179,1 \mathrm{~mm} ;$

Gear Crown Width:

$b_{1}=b_{2}+4$

$b_{1}=39+4=43 \mathrm{~mm}$

The result of the calculation of the cylindrical gear is written in table 3 .

Table 3: The main parameters of the gear spur gear

\begin{tabular}{|c|c|c|c|}
\hline \multicolumn{4}{|c|}{ Design calculation } \\
\hline Parameter & Value & Parameter & Value \\
\hline $\begin{array}{c}\text { Center distance } \\
a_{\mathrm{w}} \\
\end{array}$ & 130 & Tooth angle $\beta$ & $15^{\circ} 18^{\prime}$ \\
\hline $\begin{array}{l}\text { Engagement } \\
\text { module } m_{n}\end{array}$ & 2,75 & $\begin{array}{l}\text { Diameter of } \\
\text { pitch circle: }\end{array}$ & \\
\hline $\begin{array}{c}\text { Gear Width: } \\
\text { Gears } b_{1} \\
\text { Wheels } b_{2}\end{array}$ & $\begin{array}{l}b_{1}=43 \\
b_{2}=39\end{array}$ & $\begin{array}{l}\text { Gearsd } d_{1} \\
\text { Wheelsd } d_{2}\end{array}$ & $\begin{array}{c}d_{1}=74,3 \\
d_{2}=185,7\end{array}$ \\
\hline $\begin{array}{l}\text { Number of } \\
\text { teeth: } \\
\text { Gears } z_{1} \\
\text { Wheels } z_{2}\end{array}$ & $\begin{array}{c}z_{1}=26 \\
z_{2}=65\end{array}$ & $\begin{array}{l}\text { The diameter of } \\
\text { the circle of } \\
\text { vertices: } \\
\text { Gearsd } d_{\mathrm{a}_{1}} \\
\text { Wheels } d_{\mathrm{a}_{2}}\end{array}$ & $\begin{array}{l}d_{\mathrm{a}_{1}}=79,8 \\
d_{\mathrm{a}_{2}}=191,2\end{array}$ \\
\hline Type of teeth & $\begin{array}{l}\text { Helical } \\
\text { gear }\end{array}$ & $\begin{array}{c}\text { The diameter of } \\
\text { the } \\
\text { circumference } \\
\text { of the } \\
\text { depressions: } \\
\text { Gears } d_{f_{1}} \\
\text { Wheels } d_{f_{2}}\end{array}$ & $\begin{array}{c}d_{f_{1}}=67,7 \\
d_{f_{2}}=179,1\end{array}$ \\
\hline
\end{tabular}

According to the calculation of the geometric parameters of a cylindrical gear transmission, a geometric scheme has been developed with the transmission parameter Figure 2.

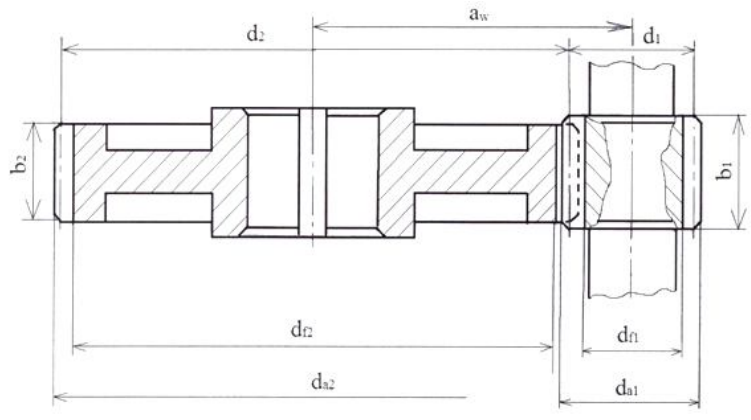

Figure 2: Diagram of transmission geometrical parameters

\section{CONCLUSION}

Thus, in this article, the geometric parameters of the cylindrical gear transmission of the gearbox are designed, the material from which this gearbox is to be manufactured is selected and the necessary calculations are made for which the cylindrical single-stage gearbox is assembled. These calculations can be used in the engineering design of the manufacture of automobiles, mechanisms and transmission elements. As a result of the calculations and the construction of a single-stage a cylindrical gearbox, you can identify the advantages and disadvantages of this type of gearbox:

Advantages of helical gears:

1. High gearbox efficiency.

2. High load capacity.

3. Low backlash of the output shaft, as a result of which the kinematic accuracy of cylindrical gears is higher than worm gears.

4. Low heat due to high gear efficiency.

5. Reversibility for any gear ratio, in other words, the absence of self-braking.

6. Confident work with uneven loads, as well as with frequent starts-stops.

7. High reliability.

8. Due to the high degree of variability of gears, it is possible to choose a gearbox with the closest gear ratio.

\section{REFERENCES}

1. Atlas of constructions of units and machine parts; MSTU named after N.E. Bauman - Moscow, 2012 .-- 400 p. 5

2. Scheinblit A.E. Course design of machine parts: Textbook. - 2nd ed., Revised and add. - Kaliningrad: Amber. Tale, 2007 .-- 454 p.

3. Y. Pratapa Reddy, Dr. K. L Narayana, Dr. M. Kedar Mallik. Electro-chemical behavior of different metals in Sodium Chloride solution // International Journal of Emerging Trends in Engineering Research Volume 7, No. November 11, 2019.

https://doi.org/10.30534/ijeter/2019/507112019

4. Smirnova Zh.V, Cherney O.T. Laser alloying technology when changing the processing speed // International Journal of Emerging Trends in Engineering Research. Volume 8. No. April 4, 2020 https://doi.org/10.30534/ijeter/2020/40842020

5. In the collection: Integration of information technology in the vocational training system. collection of articles on the materials of the regional scientific-practical conference. Nizhny Novgorod State Pedagogical University named after K. Minina. 2016.S. 24-27.

6. Yatsun, S.F. Kinematics, dynamics and strength of machines, instruments and equipment: a training manual [Text]: S.F. Yatsun, V.Ya. Mishchenko, E.N. Politov - M: Alpha-M: INFRA-M, 2012.-208s. 